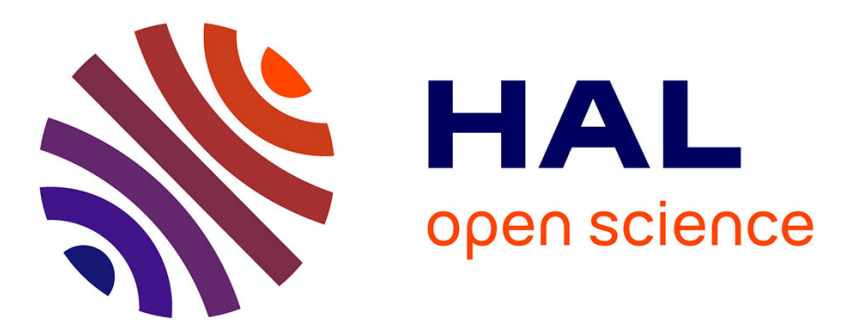

\title{
A Study of Communication Modalities in a Virtual Collaborative Task
}

\author{
Jinling Wang, Amine Chellali, Caroline Gl Cao
}

\section{To cite this version:}

Jinling Wang, Amine Chellali, Caroline Gl Cao. A Study of Communication Modalities in a Virtual Collaborative Task. IEEE SMC 2013, Oct 2013, Manchester, United Kingdom. In press. hal00903617

\section{HAL Id: hal-00903617 https://hal.science/hal-00903617}

Submitted on 12 Nov 2013

HAL is a multi-disciplinary open access archive for the deposit and dissemination of scientific research documents, whether they are published or not. The documents may come from teaching and research institutions in France or abroad, or from public or private research centers.
L'archive ouverte pluridisciplinaire HAL, est destinée au dépôt et à la diffusion de documents scientifiques de niveau recherche, publiés ou non, émanant des établissements d'enseignement et de recherche français ou étrangers, des laboratoires publics ou privés. 


\title{
A Study of Communication Modalities in a Virtual Collaborative Task
}

\author{
Jinling Wang \\ Department of Biomedical, Industrial, \& Human Factors \\ Engineering \\ Wright State University \\ Dayton, OH, USA \\ jinling.wang@wright.edu
}

\author{
Amine Chellali \\ Department of Surgery \\ Cambridge Health Alliance \\ Cambridge, MA, USA \\ amine.chellali@issyl-lab.org
}

\author{
Caroline G.L. Cao \\ Department of Biomedical, Industrial, \& Human Factors Engineering \\ Wright State University \\ Dayton, OH, USA \\ caroline.cao@wright.edu
}

\begin{abstract}
This paper examined the relative effectiveness of three communication modalities in a collaborative virtual environment. Communication modalities of verbal only (V), haptic only $(H)$, and both (HV), were used in a 2D pointing task. A total of 36 participants were paired into 18 dyads. In each dyad, there was a supervisor and an acting agent. The supervisor used one of the three modalities to guide the acting agent to reach the target location. The time to task completion and the trajectory were recorded and analyzed. The results indicate that subjects using verbal only and haptic+verbal communication performed equally well in the collaborative pointing task. Subjects using haptic only communication spent more time and had longer path lengths than verbal only and haptic+verbal communication. Nevertheless, all three modalities were effective in communicating in a virtual collaborative task.
\end{abstract}

Keywords- haptic communication; communication modality; collaborative virtual environment; pointing task; human computer interaction

\section{INTRODUCTION}

In face-to-face situations, individuals use different means and strategies to enhance their communication. For instance, non-verbal cues such as facial expressions and body language are usually combined with verbalization to ensure information is correctly transmitted and understood by the partner. However, these non-verbal cues are typically non-existent in mediated situations such as collaboration in shared virtual environments. Communication with a remote partner in a shared virtual environment becomes more complicated, increasing misunderstanding between partners [1]. In order to enhance communication in these environments, new forms of collaborative interaction, such as haptic communication, are being explored.

Compared to vision or hearing, haptics is a more direct form of human-human interaction. It can be used to express feelings of closeness or intimacy with another person [2]. It can also be used in collaborative manual tasks in which the human operators share information about the forces they apply, the movements they perform, or the positions of objects they manipulate. Physical contacts form a shared symbolic meaning between the operators, allowing them to synchronize their actions towards a common goal [3].

Unlike research with other means of communication, haptic communication and mediated haptic communication have not received much attention. This may have been due in part to the fact that physical contacts between partners at distance are difficult to reproduce faithfully. This limits the use of touch for mediated interpersonal interaction. With the advent of new technology, haptic communication becomes feasible, even remotely, giving new consideration to the haptic dimension of mediated communication [4]. This haptic mediated communication metaphor has been defined as "the ability of one actor to touch another actor over a distance by means of tactile or kinesthetic feedback technology" [3].

Haptic mediated communication in virtual environments is expected to enhance the mutual understanding between partners when they perform collaborative tasks, when other communication channels cannot be used efficiently.

In the field of collaborative virtual environments (CVEs), few studies have addressed haptic communication. Past research in this area focused mainly on the effects of this communication modality on task performance, such as building a virtual sculpture [5], co-manipulating a virtual object $[4,6$, 7], learning a surgical skill [8], and teaching handwriting [9]. These studies showed that haptic communication can improve users' performance in those manual tasks. They also showed that haptic interactions have positive effects on the sense of presence in virtual environments [4] and the sense of copresence with a remote partner in a CVE [6, 7]. Partners enjoy the communication experience through the haptic sense and 
feel more confident when interacting with each other [6]. Our preliminary research using a collaborative virtual pointing task has shown that haptic communication can be achieved through various strategies which mimic common patterns of verbal communication [10]. Parallel strategies were identified in conditions where subjects used haptic communication only or verbal communication only to accomplish the collaborative pointing task. It is not clear whether these two communication modalities could enhance performance when used together.

This study investigated the effects of using both verbal and haptic channels on the performance of a collaborative pointing task. The hypothesis was that haptic communication could enhance a collaborative task in the VR environment when critical information is not available to all.

The results of this study will contribute to the design of multimodal systems that support haptic interaction as an additional means of communication in virtual environments.

\section{Methods}

\section{A. Subjects}

A total of 36 subjects participated in this study: 21 males and 15 females, aged 18-70. They were randomly paired to form 18 dyads. Without prior knowledge about the experimental task (see details below), the subject in each dyad who sat first at the workstation without the mouse was in the role of Supervisor and labeled "Participant A", while the other one in this dyad was Acting Agent and labeled "Participant B".

\section{B. Experimental Task}

A 2D pointing task was used in this study. Subjects in this study worked collaboratively, but remotely, in pairs to perform the pointing task in a shared virtual environment. The subjects had two different roles: Supervisor and Acting Agent. Information about the location of the target and the pointer in the pointing task was known only to the Supervisor who had no control over the pointer, while the Acting Agent had control of the pointer using a mouse, but no knowledge of the target location. Since the dyads were not co-located, the Supervisor must guide the Acting Agent to the target location either by talking (verbal only, V), or using haptic feedback through a haptic device (haptic only, $\mathrm{H}$ ), or a combination of the two modalities (haptic+verbal, HV).

Subjects performed the task in six blocks, each block consisting 16 trials of randomly presented target locations in the CVE. The target location was related to the Index of Difficulty (ID) as expressed in Fitts' law:

$$
\mathrm{ID}=\log _{2}\left(1+\frac{D}{W}\right)
$$

where $D$ is the distance between the starting point and the target location, and $W$ is the width of the target measured along the axis of motion. In each block, there were four different IDs with the value of $2.0,2.5,3.0$, and 3.5. For each ID, there were 4 different target locations around a common starting point. At the beginning of each block, the subjects were told which communication modality to use $(\mathrm{H}, \mathrm{V}$, or HV). The subjects switched either their roles (from Supervisor to Acting Agent, and from Acting Agent to Supervisor), or communication modalities after each block of trials, depending on the experimental condition. The communication modality conditions were counter-balanced, while the starting role of the subjects was randomized.

\section{Experimental Setup}

The setup of the CVE used is shown in Fig. 1. A starting position, (indicated by the yellow square in the center of the monitor), the cursor position (red square), and the target (green square) were presented on a monitor to the Supervisor. The Acting Agent had a similar view of the virtual environment, but without the target. The subjects sat in front of their respective monitors, placed side by side. A curtain was drawn between them to avoid observing the other subject's body language or display. The Acting Agent could control the motion of the cursor on the computer monitor with a mouse. This motion could be observed on both monitors. Although the Supervisor could not control the motion of the cursor, he/she could use haptics and/or verbal utterances to provide instruction to the Acting Agent to guide the cursor to the target location. The haptic feedback was implemented by a haptic link between two haptic devices (PHANToM Omni, SensAble Technologies). Each Omni device had 6 degree-of-freedom (DOF) positional sensing and provided 3 DOF force feedback. Using the haptic link, the Acting Agent, holding the stylus of the haptic device, could feel the movement of the Supervisor's stylus.

Before the experiment, subjects were allowed to see each other's monitor screen simultaneously and experience the haptic link. The order of communication conditions was counterbalanced, resulting in 6 distinct orders of conditions. Three dyads were randomly assigned to one of these 6 conditions. All sessions were recorded by a camcorder. The task completion time and the trajectory for each target were recorded by the computer program for off-line analysis. Results from the analysis of the performance data are presented here.

\section{RESULTS}

Time to task completion as a function of ID for each communication modality is shown in Fig. 2. The average task completion time for all three modalities fit a linear trend line with similar slopes. This suggests that the collaborative pointing task can be described by Fitts' law, and that all three modalities were effective, to varying degrees, in achieving the task goal.

Analysis of variance results show significant main effects for the factors of order $(\mathrm{F}(5,90)=4.54 ; \mathrm{p}<0.001)$ and modality $(\mathrm{F}(2,90)=16.79 ; \mathrm{p}<0.001)$. A significant interaction effect between order and modality was also observed $(\mathrm{F}(10,90)=3.50$; $\mathrm{p}<0.001)$. 


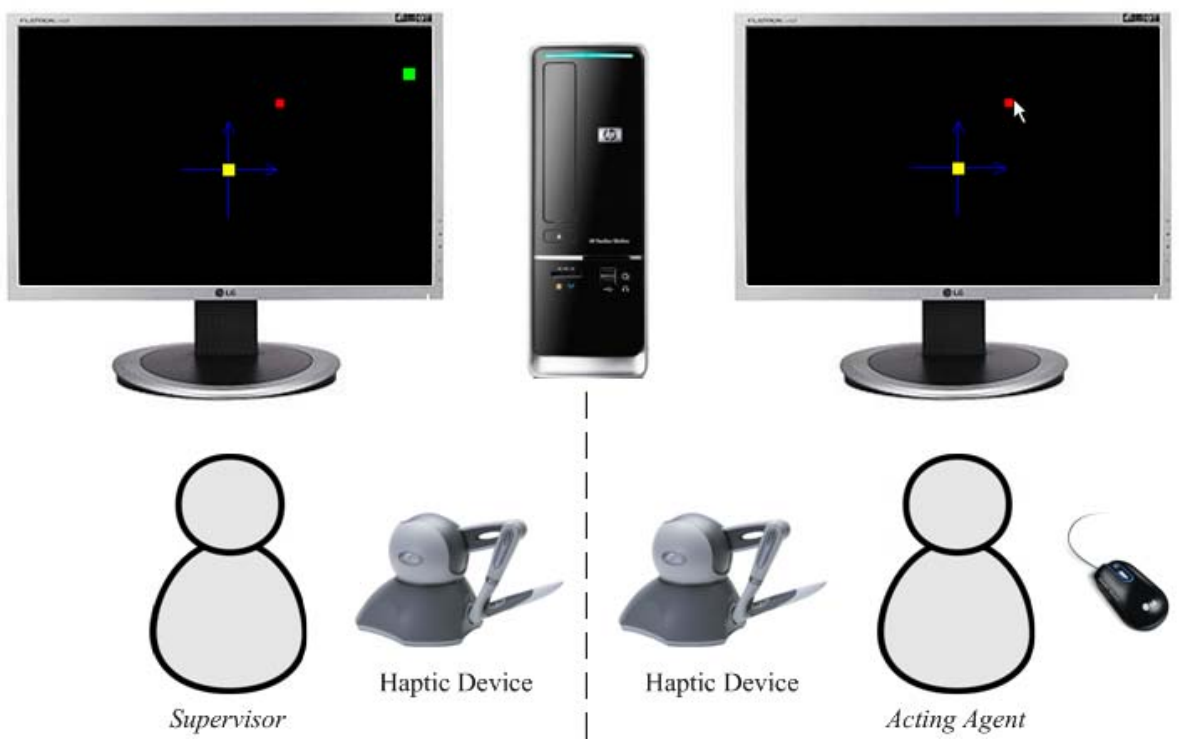

Figure 1. Setup of the experimental system.

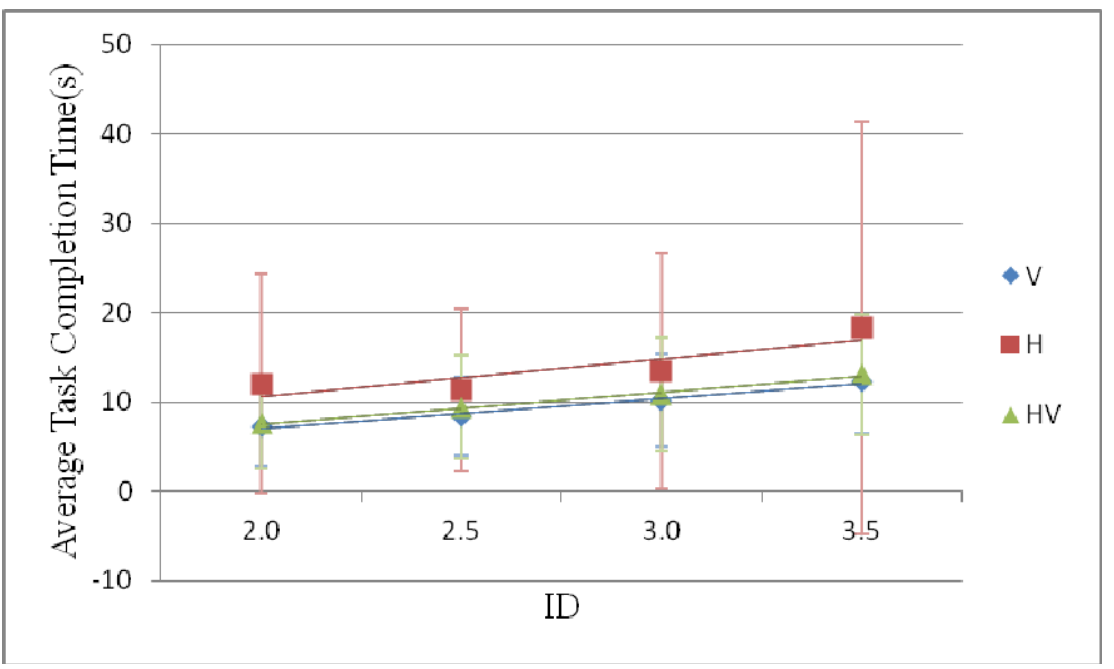

Figure 2. Task completion time as a function of ID for various modalities.

Post-hoc Tukey HSD results for modalities show that there was a statistically significant difference between $\mathrm{V}$ and $\mathrm{H}$ as well as between $\mathrm{H}$ and $\mathrm{HV}$. V and $\mathrm{HV}$ were not statistically significant. The results for orders show that there was significant difference between V-H-HV and H-V-HV as well as $\mathrm{H}-\mathrm{V}-\mathrm{HV}$ and $\mathrm{HV}-\mathrm{H}-\mathrm{V}$. All other orders were not significantly different from one another.

The average task completion time for $\mathrm{V}$ and $\mathrm{H}$ with the orders of $\mathrm{V}-\mathrm{H}-\mathrm{HV}$ and $\mathrm{H}-\mathrm{V}-\mathrm{HV}$ are presented in Fig. 3. The task completion time in the $\mathrm{H}$ condition was significantly longer than in $\mathrm{V}$, but only when subjects used haptics only before they were allowed to use verbal communication. That is, if the haptic modality was introduced to the participants after the verbal modality, the participants' performance was much better than those participants who start with the haptic modality.

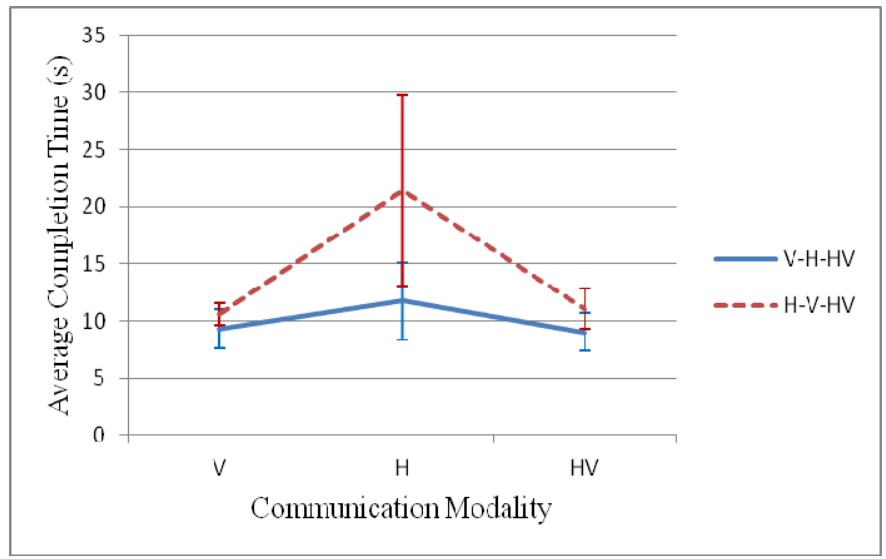

Figure 3. Task completion time for $\mathrm{V}$ and $\mathrm{H}$ with the orders of $\mathrm{V}-\mathrm{H}-\mathrm{HV}$ and $\mathrm{H}-\mathrm{V}-\mathrm{HV}$. 
More interestingly, if $\mathrm{HV}$ was introduced to the participants first, the task completion time for $\mathrm{H}$ was much reduced in $\mathrm{HV}$ $\mathrm{H}-\mathrm{V}$ compared with H-V-HV. Fig. 4 shows the completion time for verbal modality and haptic modality with the orders of HV-V-H and HV-H-V. During the experiment, it was observed that certain strategies for haptic communication could be developed during the $\mathrm{HV}$ condition. Thus, $\mathrm{H}$ modality, if it was after $\mathrm{HV}$, was more efficient than the one that started with $\mathrm{H}$.

The Tukey HSD result shows that there was no significant difference between $\mathrm{V}$ and HV. Fig. 5 shows the task completion time for $\mathrm{V}$ and $\mathrm{HV}$ with the orders of $\mathrm{V}-\mathrm{HV}-\mathrm{H}$ and $\mathrm{HV}-\mathrm{V}-\mathrm{H}$. As for the comparison between $\mathrm{H}$ and HV, the Tukey HSD result indicates that there was a significant difference. The completion time for HV was shorter than H. Fig. 6 shows the task completion time for H-HV-V and HV-H-V. The Tukey HSD result indicates that there was no significant difference between these two orders. As can be observed from Fig. 6, no matter which modality (either $\mathrm{H}$ or HV) was used first, it improved the performance of the other one.

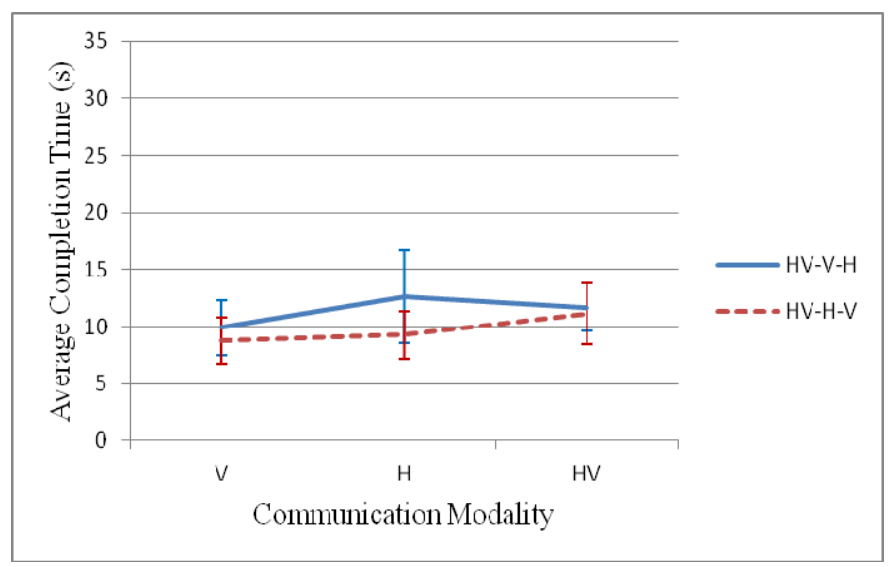

Figure 4. Task completion time for $\mathrm{V}$ and $\mathrm{H}$ with the orders of $\mathrm{HV}-\mathrm{V}-\mathrm{H}$ and HV-H-V.

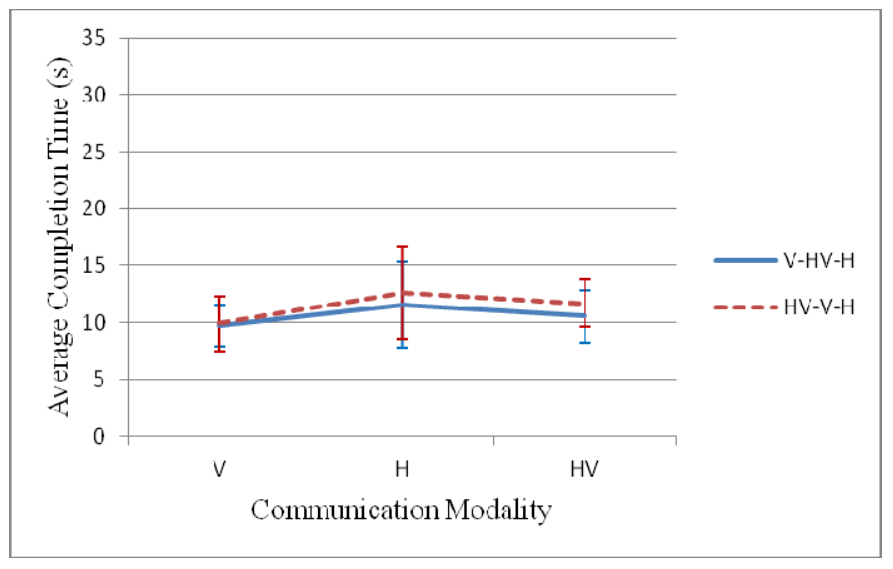

Figure 5. Task completion time for $\mathrm{V}$ and $\mathrm{HV}$ with the orders of $\mathrm{V}-\mathrm{HV}-\mathrm{H}$ and $\mathrm{HV}-\mathrm{V}-\mathrm{H}$.

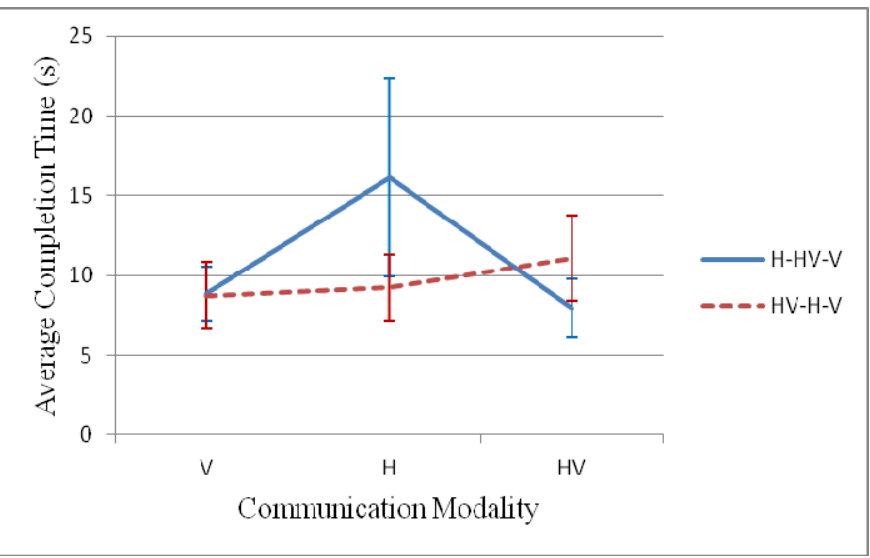

Figure 6. Task completion time for $\mathrm{H}$ and $\mathrm{HV}$ with the orders of $\mathrm{H}-\mathrm{HV}-\mathrm{V}$ and $\mathrm{HV}-\mathrm{H}-\mathrm{V}$.

Besides the task completion time, the mouse trajectory for each target location was analyzed. Since different IDs were involved in this study, the ideal shortest distance from the starting point to the target location varied. The relative path length, which was defined as the ratio of the actual path length to the ideal shortest path, was used to compare the performance in each trial. Fig. 7 shows the average of the relative path length for each modality and order. The analysis of variance results show that there was a significant main effect of order $(F(5,90)=13.16 ; p<0.001)$, modality $(F(2,90)=34.62 ; p<0.001)$, and interaction $(\mathrm{F}(10,90)=13.58 ; \mathrm{p}<0.001)$. Post-hoc Tukey HSD results for modalities show that there was a significant difference between $\mathrm{V}$ and $\mathrm{H}$ as well as between $\mathrm{H}$ and $\mathrm{HV}$. V and HV were not statistically significant. The results for orders show that there was statistically significant difference between $\mathrm{H}-\mathrm{V}-\mathrm{HV}$ with the other 5 orders, and the difference amongst the rest of the order combinations were not significant.

Fig. 7 shows that $\mathrm{H}$ was the least efficient modality in this task, while the efficiency of $\mathrm{V}$ and $\mathrm{HV}$ were similar. In each of the 6 orders, $\mathrm{H}$ has the longest relative path length with a large standard deviation $(\mathrm{SD}=7.88)$.

\section{DISCUSSION}

This study investigated the relative effectiveness of three communication modalities $(\mathrm{V}, \mathrm{H}$, and $\mathrm{HV})$. It was found that all these three modalities were effective means to communicate the information in a $2 \mathrm{D}$ collaborative pointing task. The task completion time of these three modalities for the four IDs fits a linear trend line which is expected in a Fitts' task. It shows that the average task completion time of the HV modality is quite close to the $\mathrm{V}$ modality. The efficiency of the $\mathrm{H}$ modality is the least and the standard deviation is the largest among the three modalities. A possible explanation for this is that the subjects involved in this study had no prior experience with haptic devices and haptic communication, while their verbal communication is well developed and can be used easily to establish common ground, even in a new environment. During the experiment, the dyads had to spend some time to develop their haptic communication strategy with their partners. Thus, the $\mathrm{H}$ modality was less efficient and more variable than the $\mathrm{V}$ modality. 


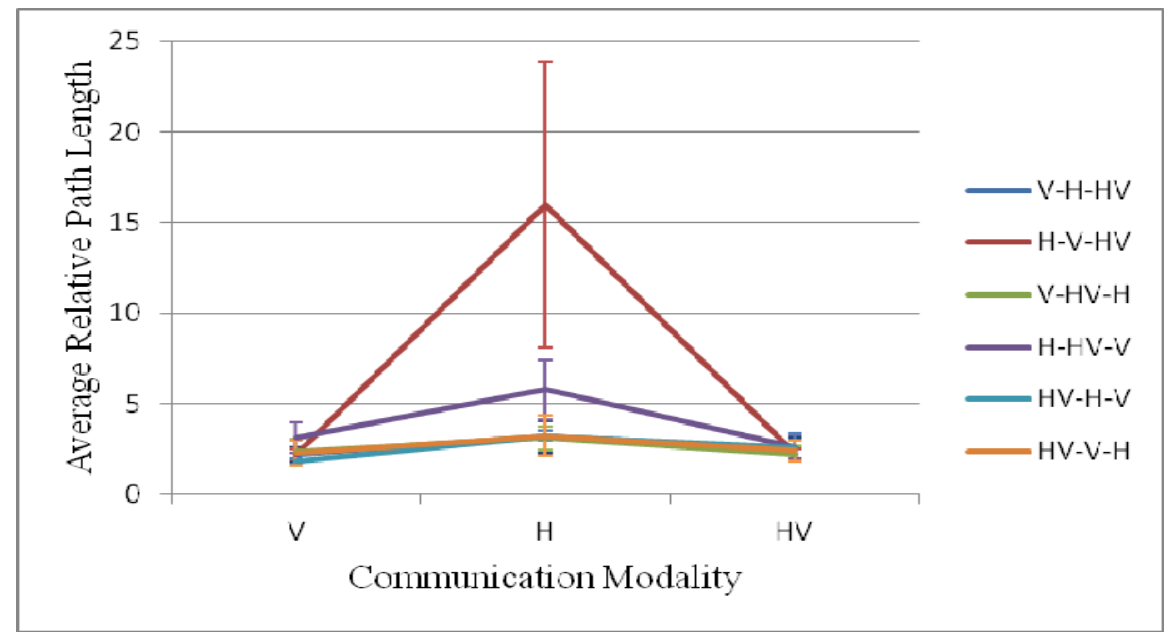

Figure 7. Average relative path length v.s. modality in 6 orders.

As for task completion time and relative path length, there was a significant effect of modality, order, and interaction. The difference between $\mathrm{V}$ and $\mathrm{H}$ as well as $\mathrm{H}$ and $\mathrm{HV}$ were significant, but the difference between $\mathrm{V}$ and $\mathrm{HV}$ was not significant. The observation from the results of task completion time was coincident with the observation from the relative path length results.

According to task completion time results, although subjects in $\mathrm{V}$ and $\mathrm{HV}$ conditions had better performance, $\mathrm{H}$ communication could be improved as the partners established some common ground with practice. The comparison between the order of V-H-HV and H-V-HV shows that the participants who started with $\mathrm{V}$ had better performance than the participants who started with $\mathrm{H}$. Moreover, the difference of task completion time for $\mathrm{H}$ in these two orders was much larger than that of V. One possible reason is that the haptic communication, unlike the well-developed verbal communication, has a larger potential to be improved by establishing the way to communicate during trials. With an order of $\mathrm{V}-\mathrm{H}-\mathrm{HV}$, the subjects might have expected to exchange spatial information in $\mathrm{H}$ as they did in $\mathrm{V}$.

Additionally, the results show that the development of communication strategies in the HV condition is more efficient than that in the H condition since the Supervisor could use the verbal communication to help the Acting Agent to build the haptic communication language based on their verbal instruction about the motion and direction in the pointing task. It could explain the significant difference between $\mathrm{HV}-\mathrm{H}-\mathrm{V}$ and $\mathrm{H}-\mathrm{V}-\mathrm{HV}$.

Furthermore, the average relative path length for $\mathrm{H}$ modality in the order of H-V-HV was longest followed by HHV-V. The only two orders starting with $\mathrm{H}$ had the worst performance, and thus it supports our previous statement that the development of the haptic communication strategy is less efficient if only $\mathrm{H}$ is used.

Even though haptic only communication was not as efficient as verbal only and haptic+verbal communication, it was nevertheless an effective means of information exchange during a collaborative task. The order effect observed in this study suggests that haptic communication was dominated by the highly familiar and well-developed verbal modality. Whether the strategies used in the first haptic only condition were different from those in the haptic only condition that followed V or HV will need to be examined next. The results will have implications for the design of multimodal interfaces for collaborative virtual environments.

\section{REFERENCES}

[1] A. Chellali, I. Milleville-Pennel, and C. Dumas, "Influence of contextual objects on spatial interactions and viewpoints sharing in virtual environments," Virtual Reality, vol. 17, pp. 1-15, 2013.

[2] E.-L. Sallnäs, K. Rassmus-Gröhn, and C. Sjöström, "Supporting presence in collaborative environments by haptic force feedback," ACM Trans. Comput. Human Interaction (TOCHI), vol. 7, pp. 461-476, 2000.

[3] A. Haans and W. IJsselsteijn, "Mediated social touch: a review of current research and future directions," Virtual Reality, vol. 9, pp. 149159, 2006.

[4] W. Buxton, "Touch, gesture \& marking," in Readings in Human Computer Interaction: toward the Year 2000, Chapter 7, R.M. Baecker, J. Grudin, W. Buxton, and S. Greenberg, Eds. San Francisco: Morgan Kaufmann Publishers, 1995.

[5] C. Gunn, "Collaborative virtual sculpting with haptic feedback," Virtual Reality, vol. 10, pp. 73-83, 2006.

[6] C. Basdogan, C.-H. Ho, M.A. Srinivasan, and M. Slater, "An experimental study on the role of touch in shared virtual environments," ACM Trans. Comput. Human Interaction (TOCHI), vol. 7, pp. 443-460, 2000.

[7] A. Chellali, C. Dumas, and I. Milleville-Pennel, "Influences of haptic communication on a shared manual task," Interacting with Computers, vol. 23, pp. 317-328, 2011.

[8] A. Chellali, C. Dumas, and I. Milleville-Pennel, "Haptic communication to support biopsy procedures learning in virtual environments," Presence: Teleoperators and Virtual Environments, vol. 21, pp. 470-489, 2012.

[9] S. Ullah, X. Liu, S. Otmane, P. Richard, and M. Mallem, "What you feel is what I do: a study of dynamic haptic interaction in distributed collaborative virtual environment," Human-Computer Interaction, Part II (HCII 2011), J.A. Jacko (Ed.), Springer-Verlag, Berlin, Heidelberg, pp. 140-147, 2011.

[10] B. Takac, A. Chellali, C. Dumas, I. Milleville-Pennel, C. Grosdemouge, and C.G.L. Cao, "Haptic communication for a $2 \mathrm{D}$ pointing task in a virtual environment," in Proc. of the Human Factors and Ergonomics Society Annual Meeting: HFES 2011, vol. 55, pp. 2168-2172, 2011. 